\title{
El derecho y los marxistas
}

\section{O direito e os marxistas}

Óscar Correas ${ }^{(*)}$

Recebido: 06/2016

Aprovado: 09/2016

\begin{abstract}
Resumen: Este trabajo se confiesa parcial desde que expresa un punto de vista latinoamericano acerca del tema derecho y marxismo. Y no sólo por la imposibilidad, en este momento, de intentar un balance global del pensamiento marxista en torno del derecho, sino por convicción política: nuestra experiencia muestra que tenemos puntos de vista distintos de los europeos y norteamericanos, además de que nos resulta difícil la comunicación con juristas que, no sólo viven realidades distintas, sino que creen que las suyas son universalizables, además de creer, demasiadas veces, que son los únicos autorizados a producir trabajos teóricos plausibles.
\end{abstract}

Palavras clave: Derecho y marxismo. Perspectivas latino-americanas. Tendencias jurídicas del marxismo.

Resumo: Este trabalho admite-se parcial, pois expressa uma perspectiva latino americana sobre o tema direito e marxismo. E não só pela impossibilidade, neste momento, de tentar um panorama global do pensamento marxista sobre o direito, mas por convicção política: nossa experiência mostra que temos pontos de vista diferentes dos europeus e norte americanos, além de ser difícil a comunicação com os juristas que não só vivem realidades diferentes, mas que também acreditam serem elas universalizáveis. Além de acreditar, muitas vezes, que são eles os únicos autorizados a produzir obras teóricas plausíveis. ${ }^{1}$

Palavras-chave: Direito e marxismo. Perspectivas latino-americanas. Tendências jurídicas do marxismo.

\section{El marxismo y los juristas marxistas}

Hemos venido hablando últimamente de "el derecho y el marxismo», tal vez todavía atados a la idea de que había un solo marxismo y una sola manera «marxista» de aproximarse al derecho. Pienso que debemos cambiar la perspectiva. En primer lugar, hay varias tradiciones que se reclaman, con derecho, marxistas. ${ }^{2}$ En segundo lugar, existen distintas tendencias entre los juristas marxistas, y valdrá la pena intentar algún balance. $Y$ en tercer lugar, los juristas marxistas están agrupados regionalmente.

Respecto de lo primero, de las diversas tradiciones marxistas, habría que decir que un intento de inventario sería riesgoso, tanto por el número de ellas como por las combinaciones posibles, en caso de que se pudiera llegar a establecer algunos modelos «puros». Por ejemplo si pudiera establecerse que las corrientes fueran leninista, althusserianas, gramscianas, lukacsiana, ¿cuántas variantes sería posible descubrir, que manifiestan influencias combinadas de varias de ellas?

\footnotetext{
* Óscar Correas Vazquez - Professor Catedrádico da Faculdad de Derecho da Universidad Nacional Autónoma do México - UNAM, coordenador-geral do celébre periódico "Revista Crítica Jurídica", em circulação há mais de 30 anos. Possui vasta produção acadêmica nas áreas de filosofia do direito, sociologia jurídica e direitos humanos.
} 
Respecto de lo segundo, que existen distintas tendencias, sabemos desde hace tiempo que en la Unión Soviética hubo dos encontradas, la de Vishinsky por un lado, y la de Pashukanis y Stucka por el otro, que han ocupado muchas páginas, y que han generado diversas obras y tendencias. Pero después de esa disputa, puede decirse que los marxistas han intentado diversas maneras de pensar el fenómeno jurídico, sin que nadie pueda decirse heredero del «verdadero» marxismo. En algún momento habrá que hacer una balance, pero mientras tanto lo mejor es dejar de hablar de el marxismo frente al derecho.

Respecto de lo tercero, es decir, que los marxistas estén agrupados regionalmente, también puede decirse que muestra como conveniente comenzar a pensar nuestra experiencia en otros términos, dejando de lado la desafortunada idea de que hay un solo marxismo o una sola manera marxista de hablar del derecho. Lo mejor, propongo, es que comencemos a hablar en términos de la relación entre el derecho y los marxistas, preguntándonos qué han hecho, y se proponen hacer, los juristas que, además de serlo, se confiesan marxistas. Nos interesa saber qué han hecho los juristas marxistas, en o para América Latina, y en qué están interesados. Y, por supuesto, entendemos que dentro de lo que han hecho y lo que pretenden hacer, están sus relaciones con el marxismo europeo actual y los otros juristas marxistas. $Y$ desde luego que también interesan sus relaciones con teorías sociales y juristas no marxistas.

\section{¿Cuál marxismo?}

En esta agenda está, entre otras cosas, la discusión acerca de lo que cada uno, o los grupos existentes, consideran marxismo. ¿Aceptamos todo Marx? ¿Cuál es la tradición marxista a la que nos afiliamos como pensadores del derecho?

Por otra parte, esta pregunta implica también la que inquiere por lo que aceptamos de otras teorías sociales, y, especialmente, de la Teoría General del Derecho tal cual ésta existe hoy.

Creo que debemos esperar otra ocasión para analizar el marxismo al que nos afiliamos. Aunque, en términos muy generales, todos estamos de acuerdo que no nos interesa el marxismo estalinista. Pero esto también deberá ser discutido: ¿a qué nos referimos con esta expresión? 


\section{Las tendencias jurídicas del marxism}

Durante un buen tiempo hemos leído y discutido la obra de los juristas soviéticos. Sabemos ya que existieron dos líneas de pensamiento, y todos hemos tomado partido en este asunto, y creo que también todos hemos repudiado las concepciones de Vishinsky, en tanto legitimadoras de un estado que detestamos. A todos nos simpatizan los intentos de la otra corriente, de fundar lo que hoy llamaríamos una teoría sociológica del derecho basada en el marxismo. Todos también, creo, tomamos distancias, unos más, otros menos, respecto de buena parte de los postulados de Pashukanis. $Y$ también, en la medida en que no nos asusta el fantasma del positivismo, aceptamos que parte de lo que sostenía Vishinsky es aceptable: entre otras cosas, el derecho contiene normas, que son distintas que las relaciones sociales. Sobre esto se han escrito algunos balances recomendables. ${ }^{3} \mathrm{Y}$ me parece que de ellos se desprende lo siguiente: 1) hasta la segunda mitad de la década de los setenta, la cuestión giraba alrededor del estudio de los juristas soviéticos, y de la construcción de una visión filosófica específicamente marxista del derecho. Me parece que Umberto Cerroni es el paradigma de este intento; 2) en adelante, comienzan a aparecer obras que, dejando de lado esa discusión, más bien usan el marxismo para hacer análisis de diversos aspectos de la vida jurídica. Y esta es la tendencia actual. Mayor razón para dejar de hablar de derecho y marxismo, para preguntar en qué se interesan y qué han aportado los marxistas. Nos debemos, entonces, este balance. Pero podemos adelantar algo.

\section{Teoría del derecho}

En algún momento los marxistas pensamos en que había que desarrollar una Teoría General del Derecho que compitiera con la del positivismo y la filosofía analítica. Eso, creo, ha sido dejado atrás en este momento. La razón es más bien simple: ésa es una buena teoría, incluso para los marxistas. En efecto ¿qué de específico podría el marxismo, partiendo de las obras de sus clásicos, agregar a los conceptos de norma, sistema jurídico, regla de reconocimiento, y otras como validez y efectividad o eficacia? ${ }^{4}$

La intención de construir tal teoría se ha venido disipando en la medida en que los marxistas, alumnos de importantes autores analíticos, se han visto obligados a las lecturas clásicas (Kelsen, Hart, Ross, Bobbio) de la moderna Teoría General del Derecho. Y puede decirse que donde la tradición analítica es menos fuerte, como en Brasil o México, los marxistas aceptan menos esta teoría, a veces al duro precio de la ingenuidad teórica respecto del derecho. ${ }^{5}$ 
Hoy puede decirse que los juristas marxistas no se sienten incómodos con los desarrollos teóricos de los analíticos. A lo más, aburridos.

Por otra parte, comienza a darse un curioso fenómeno de reversión: autores de background marxista retoman a Kelsen, pero un Kelsen "olvidado» por los analíticos, encontrando en sus obras sorprendentes doctrinas mucho más próximas al pensamiento emancipatorio que al analítico. ${ }^{6}$ Principalmente es la última teoría kelseniana de la norma fundante la que ha sacado de quicio a los analíticos, doctrina respecto de la cual se vienen haciendo los distraídos, o bien calificándola de "contradictoria» o «irracional». Me refiero a que Kelsen, al final de su vida, y con mucha congruencia respecto de obras como Dios y estado, dijo que la grundnorm es una ficción.

En fin, podemos decir que, en lo sucesivo, no sólo los marxistas aceptarán la Teoría General del Derecho positivista, ${ }^{7}$ sino que la llevarán hasta sus últimas consecuencias, seguramente entre el griterío y los más terribles anatemas de los analíticos, que sentirán que Kelsen les quitó, al final de su vida, la escalera con que los hizo subir (Cárcova dixit).

\section{Filosofía, teoría y ciencia políticas}

La mayor parte de los juristas marxistas no ha podido, afortunadamente, separar la reflexión sobre el derecho, de los temas del poder y el estado. En los últimos años, posiblemente ha sido en estos rubros que el aporte de los juristas marxistas ha sido el más importante. Pero merece un balance aparte.

\section{Teoría sociológica del derecho y sociología jurídica}

No cabe duda de que si hay un campo propicio para el estudio de los fenómenos relacionado con el derecho, desde la teoría marxista, ese campo es el de la Sociología. Y de hecho, hace algunos años que venimos encontrándonos en foros internacionales convocados bajo el paraguas de la Sociología Jurídica. Nos debemos un balance, pero podemos adelantar que algunos de los temas que han interesado a los juristas marxistas, son:

Erro! Argumento de opção desconhecido..Los intentos de lograr una Teoría Sociológica del Derecho: es decir, el intento de desarrollar la famosa idea de que el derecho se explica a partir de las relaciones sociales. Puede decirse que todos los intentos tratan de superar el llamado "economicismo» del que el marxismo ha sido acusado tantas 
veces.

Erro! Argumento de opção desconhecido..Las transformaciones contemporáneas del derecho y el estado. Como no podía ser de otro modo, han estado atentos a todos los procesos, pero especialmente a la democratización de nuestras sociedades latinoamericanas. Es posiblemente el aspecto en que más han trabajado.

Erro! Argumento de opção desconhecido..La explicación del derecho moderno. El marxismo ofrece, como ninguna otra teoría social, posibilidades para explicar el contenido de las normas y la ideología del derecho moderno.

\section{Otras disciplinas}

Erro! Argumento de opção desconhecido.. Semiología o Semiótica: buena parte de los juristas marxistas han visualizado al derecho como discurso. Eso los puso en la huella de ciencias del lenguaje como la Semiología o Semiótica. Sin embargo, difícilmente el marxismo tenga elementos que mejores las teorías lingüísticas y semióticas creadas por tradiciones no marxistas. Por eso, en este punto, los trabajos de los marxistas difícilmente se reconocen como tal. Habría que decir que se trata de autores de background marxistas, pero que se dedican a otras disciplinas.

2. Control social: algunos, juristas cuyo origen era el derecho penal y la criminología, han desembocado en una disciplina más general y, parece, moderna, que denominan Sociología del control penal.

3. Psicoanálisis: casi todos se han interesado por el tema de la subjetividad, y algunos se han sumergido a fondo en el pensamiento de Freud y sus seguidores.

\section{La enseñanza del derecho}

La educación jurídica, como no podía ser menos en seguidores del Marx de la Ideología Alemana, los marxistas han reflexionado sobre la educación de los juristas, han participado en las universidades, y han intentado cambios, cosa 
que no puede decirse que hayan hecho, con la misma tenacidad, los juristas de las otras tendencias.

\section{Los servicios legales alternativos}

Los servicios legales alternativos son tema obligado para los juristas marxistas. La revista El otro Derecho, de Bogotá, es un ejemplo de esta preocupación. Se entiende que los marxistas no puede dejar de tener un punto de vista teórico acerca de esta actividad en la que participan tantos compañeros. ¿Cuánto vale el argumento de que usar el derecho moderno es contribuir a la reproducción de las relaciones sociales capitalistas? ¿Cuáles son los resultados obtenidos hasta hoy en estas actividades? Preguntas como ésa. y otras muchas acerca de la práctica de los abogados, han sido motivo de reflexión. Al respecto también podría hacerse un balance más adelante.

\section{Derechos Humanos}

Todo marxista sabe, por experiencia, que los derechos humanos se defienden, en primer lugar, en la calle. Eso los diferencia claramente de la tendencia actualmente dominante en Teoría General del Derecho. Me refiero a los teóricos analíticos que, como los hongos, salen a defender los derechos humanos después de la tormenta, es decir, cuando ya no hay peligro. Los hemos visto; mejor: no los hemos visto cuando se trataba de llegar a las estaciones de policía a preguntar por los presos, a la hora de defenderlos en los tribunales, en el momento en que era necesario que su prestigio académico se agregara a los cientos de juristas que defendían los derechos humanos y la democracia frente a las dictaduras en turno. Eso sí, a la hora de acceder a los puestos oficiales de defensa de derechos de la población, pasadas las dictaduras, son los primeros en la fila. Y, desde luego, los primeros en hablar del fundamento filosófico de los derechos humanos y la democracia. Bienvenidos. Pero los derechos humanos se defienden en la calle. Y eso porque son un asunto político, y sólo porque lo son, son, además, un problema ético.

Para los marxistas, los derechos humanos son el discurso propio de la sociedad burguesa; o «moderna» como se dice ahora. Esto es, constituyen un discurso político, históricamente situado: nacieron con nuestra sociedad y no antes. $Y$ por eso los marxistas se sienten más cómodos en la sociología, la semiótica y la historia de los derechos humanos, que en su fundamentación filosófica. Posiblemente el pensamiento marxista, como tal, no puede ofrecer una 
justificación «marxista» de ellos, ni una justificación mejor que la de otras tendencias filosóficas no iusnaturalistas. $Y$ en este punto vale decir lo siguiente: en la calle, los marxistas encuentran como compañeros a los iusnaturalistas y jamás a los analíticos. Sin embargo, pueden sentirse más cómodos con las justificaciones filosóficas de los analíticos que con las de los iusnaturalistas. Ésta es una paradoja, al parecer inevitable: el iusnaturalismo puede ser una actitud contestataria de la sociedad burguesa; la filosofía analítica no tiene tal vocación.

Siendo así que los derechos humanos son un asunto político, son también un instrumento de lucha por una sociedad más justa. No son un fin en sí mismos, como no lo es ninguna norma; el objetivo es la sociedad justa, que los hombres hoy oprimidos vivan mejor. $Y$ para lograrlo, entre otras muchas cosas, es necesario defender los bienes que postula este discurso llamado derechos humanos. La posición según la cual los derechos humanos son un fin en sí mismos ve al derecho como fin y no como instrumento, y en eso sí hay una diferencia importante.

Quienes sostienen la postura de que se trata de un fin en sí mismos, creen que reconocer el carácter político de los derechos humanos puede llevar a su negación. Dicen algo así como: si creemos que son un instrumento para otro fin, entonces pueden ser torcidos o violentados cuando no convienen a ese fin. Pero lo que pasa es que eso es imposible: no hay vida mejor sin que se obtengan esos bienes que postulan los derechos humanos tal como los conocemos hoy.

Desde el punto de vista político, los derechos humanos constituyen la condición de una regla técnica: si queremos una vida mejor, entonces tenemos que lograr el respeto a los derechos humanos; o bien: el respeto a los derechos humanos es la condición sine qua non de una vida mejor. La otra visión ve los derechos humanos como valores que fundamentan normas, morales o jurídicas.

Ahora bien, hay una dificultad con las enumeraciones o elencos de los derechos humanos. Según cual sea el organismo que se arrogue el derecho de decir cuáles son los derechos que deben defenderse, los bienes defendidos cambian. Por ejemplo, los gobiernos del primer mundo consideran que los derechos defendibles son los de su cultura y sus constituciones. Pero los países del tercer mundo, en muchas casos, tienen opiniones distintas. Esta cuestión no ha podido sanjarse y está en la mesa del debate. Puede decirse que la reticencia de los juristas del tercer mundo no proviene tanto de la concepción acerca de los bienes que deben defenderse con los derechos, sino del uso que los países militarmente poderosos hacen del discurso de los derechos humanos. Por ejemplo ¿quién en su sano juicio podría decir que la guerra de EEUU y sus satélites contra Irak, fue por la defensa de los derechos humanos de los Kuwaitíes?

Pero de todos modos, sin querer considerar este uso de los derechos 
humanos que hacen los países primermundistas, los juristas analíticos, ahora a la búsqueda de fundamentaciones universales de la ética, creen que debe lograrse una enumeración universal de derechos, y que deben ser defendidos en calidad de valores indiscutibles. $Y$ en esa tesitura, resulta que los marxistas son condenados porque están siempre a favor de los obreros, los pobres, los campesinos, los oprimidos, «olvidando los derechos humanos de los otros sectores sociales. $\mathrm{Y}$ así es en efecto: en la defensa de los derechos de los oprimidos siempre se llega al enfrentamiento con los derechos de los opresores. La posición de los juristas no marxistas es, siempre, que hay que parar la lucha en el momento en que se da este enfrentamiento. Los marxistas, en cambio, sostienen, en los hechos, que no es así. Esta diferencia de opiniones es inevitable, porque para los marxistas los derechos humanos constituyen medios de defender bienes que han sido conquistados en la lucha contra los opresores. Son conquistas de la humanidad, pero en el tránsito hacia una sociedad mejor. Y por cierto que no es válido que ahora los opresores los usen para desactivar la lucha que los oprimidos deben continuar desarrollando contra su intransigencia.

En este punto no habrá coincidencia, porque los marxistas piensan que el imperativo ético, el fin en sí mismo, es el socialismo y el comunismo, y no los derechos humanos. $Y$ si los derechos humanos no defienden la lucha por la vida buena, entonces no son tan interesantes.

Ahora bien, esta disputa teórica, no debería afectar la militancia de todos los juristas democráticos. La verdadera cuestión es la posición política que adoptamos, a cuál partido apoyamos, a qué invasiones defendemos, a quien le prestamos consejo profesional. Y me temo que los juristas analíticos sólo están interesados en la discusión teórica. Por eso es que más bien son ellos quienes tienen que probar que están, en serio, comprometidos con los derechos humanos. Porque entre los marxistas ya hay muchos muertos...

\section{La Democracia}

Con la democracia pasa lo mismo que con los derechos humanos. Tal vez porque muchos los identifican. Y la posición es la misma: la democracia no es un fin en sí misma. El objetivo es una vida buena, que los marxistas identifican con el socialismo y el comunismo. La democracia es un instrumento para lograrlo. Y si no lo logra, o no es democracia, o la democracia no sirve.

Si la democracia se define como sistema de normas que sirve para crear otras normas, y se entiende que eso es un fin en sí mismo, entonces la democracia puede conducir a sociedad profundamente injustas. Y ése parece 
ser el caso de las democracias del mundo contemporáneo. Y si ése es un fin en sí mismo, desde luego que los marxistas estarán en desacuerdo.

Por otra parte, los juristas del primer mundo, identifican la democracia con sus formas de gobierno. Pero sus sistemas dejan mucho qué desear...

Ahora bien, si la democracia es un conjunto de normas que tiene como objetivo la construcción de una sociedad de hombres que conviven fraternalmente, la democracia es un instrumento. $Y$ por tanto no hay democracia si no conduce a esa sociedad mejor. Pero frente a quienes ven a la democracia como fin en sí mismo, y que por tanto no la ven como instrumento de una vida mejor, los marxistas deberán decir que esa democracia no sirve. Lo irrenunciable es el objetivo político: la construcción de una sociedad estable y justa. Y la cuestión depende de cómo definamos «democracia».

Ahora bien, ¿qué sería una sociedad justa? No son los marxistas los llamados a titubear: una sociedad justa es una socialista o comunista, que ha sido imaginada por todo el pensamiento libertario que se conoce. En este punto las cosas están claras entre los juristas marxistas y quienes no lo son. Y mucho más desde que los marxistas latinoamericanos no tienen que defender ningún poder; el problema es para los socialistas europeos que tienen que mostrar su consistencia ética, al apoyar a un gobierno, que dicen que es democrático, pero que no parece conducir a otra cosa que al continuo engorde del capital, y a costa de mucha sangre, especialmente del tercer mundo. Para los juristas marxistas latinoamericanos, la cosa está clara: si esa democracia es todo lo que hay que esperar, porque es un fin en sí mismo, no interesa.

\section{La Seguridad Jurídica}

Los juristas marxistas sabemos muy bien cuáles son los beneficios y los límites del postulado político de la seguridad jurídica. Podemos hacernos algunas preguntas. ¿Estamos de acuerdo con el uso de la fuerza legitimada por el derecho, para garantizar la posición actual de los que han heredado la tierra que sus antepasados les quitaron a los habitantes originarios de América (o África o donde sea que el capitalismo sentó sus reales?) ¿Estamos de acuerdo con la seguridad, brindada por el derecho, a los capitalistas que han amasado fortunas con la sangre de los obreros? ¿Estamos con los zapatistas y los indios ecuatorianos, hoy en pié de guerra? ¿O estamos con los terratenientes que tienen derecho a la seguridad en el usufructo de sus propiedades?

Por otra parte ¿queremos seguridad en los derechos ya adquiridos por los oprimidos, aunque no se cumplan?

Éste parece ser el dilema: o la seguridad jurídica es un fin en sí mismo, o 
la seguridad es un instrumento para la lucha de los oprimidos contra sus verdugos. Los juristas marxistas están siendo chantajeados en este punto: si quieren seguridad para sus defendidos, tienen que aceptarla para los explotadores, «que son tan humanos como los otros». A lo que hay que contestar: interesa la seguridad jurídica, pero no para los explotadores. ¿Estamos con los campesinos que invaden su antigua tierra hoy en manos de los capitalistas? ¿O estamos con las fuerzas que los desalojan porque hay que brindar seguridad a los propietarios actuales?

Y cuando los marxistas dicen que están con los campesinos, entonces se les acusa de generar la violencia. ¡Como si el despojo y la explotación no hubieran sido violencia! «Bien, dicen; pero eso fue antes; ahora hagamos las cosas de otro modo; aseguremos el derecho y la democracia, que todo vendrá por añadidura». Es como ofrecer paz en una carrera en la que alguno ya sacó cinco siglos de ventaja, y le pide a los otros que se sujeten a las normas que produjo el que se adelantó, todo en nombre de la democracia y la seguridad jurídica.

Un contraargumento suele ser: «pero es que los propietarios de ahora no son los mismos que hicieron el despojo; los actuales no tienen la culpa». Se parece al pensamiento español: los ibéricos de ahora no tienen nada qué ver con los de la conquista; tampoco tienen nada qué ver con los españoles que encontraron asilo y trabajo hace sesenta años, y por lo tanto nada se les debe a los latinoamericanos. Parece plausible; pero hay algo que no termina de convencernos y no sabemos qué es.

El problema de la seguridad jurídica debe ser resuelto con argumentos que tengan en cuenta algo que últimamente se viene perdiendo de vista: la sociedad actual es injusta y está dividida en clases y grupos sociales, algunos de los cuales explotan y oprimen a los otros. No puede resolverse sobre la base de una imagen ficticia del mundo moderno, como quieren los teóricos de la democracia a la europea, que además ignoran, para todos los efectos posibles, la existencia del tercer mundo. (Lo cual corre parejo con el ninguneo, ${ }^{8}$ por buena parte de los juristas primermundistas, del pensamiento crítico americano - no del pensamiento analítico, por supuesto, que no tiene ninguna intención de contestar el mundo europeo).

Podría decirse que la seguridad jurídica es un instrumento aceptable, siempre que no se oponga al goce de los bienes que los derechos humanos postulan como defendibles. ¡Ah! Y me olvidaba: entre los derechos humanos no se encuentra el de disponer individualmente, ni de los medios de producción, ni de su producto. Y si aparece en algunos catálogos, es porque fue introducido de contrabando por los capitalistas y sus juristas. 
${ }^{1}$ Este artigo nos foi enviado pelo eminente Professor Óscar Correas, Catedrático da Faculdad del Derecho da UNAM - Universidad Nacional Autónoma del México. Por sua enorme relevância, já teve várias publicações (inclusive por nós), mas pela atualidade e pertinência ao debate para a Filosofia do (e sobre o) direito, para a filosofia do direito dos filósofos e aquela outra, dos juristas, optamos em reeditá-lo na secção de ensaios da presente edição especial da Revista 'Problemata' sob nossa responsabilidade. A tradução do resumo é da pesquisadora Juliana Coelho Tavares da Silva, membro de nosso Núcleo de Pesquisa sobre "Marxismo, Realismo e Filosofia do Direito".

2 Esto había sido apuntado ya en América Latina: Correas, Oscar, «Kelsen y las dificultades del marxismo» en Crítica Jurídica Puebla, UAP, 1987, núm. 5, pp. 51 y ss, Cárcova, Carlos María, «Acerca de las relaciones entre marxismo y derecho» en Teorías Jurídicas alternativas, Buenos Aires, Centro Editor de América Latina, 1993, pp. 71 y ss.

3 Porque ha sido publicado en América Latina, por una editorial de la que se espera buena distribución, con seguridad tiene vocación de convertirse en un texto que será leído, e influirá en este balance que nos debemos, el de Atienza, Manuel y Ruiz Manero, Juan, «Marxismo y ciencia del derecho» en Marxismo y Filosofía del Derecho, México, Fontamara, 1993, p. 67 y ss. Es claro que, como dicen los autores, el texto trata más que nada sobre la cuestión de la ciencia jurídica, y por ello entienden la dogmática, mientras que, como ellos también dicen, no es allí donde el marxismo puede aportar algo interesante. Esto quiere decir que el balance, en términos de Sociología Jurídica y Crítica del Derecho, no se ha realizado aún. Por otra parte el texto no explora todo el marxismo, ni mucho menos. Y menos intenta ninguna reflexión sobre los marxistas latinoamericanos, a quienes sin duda conocen. Tampoco intentan una reflexión sobre el marxismo jurídico anglosajón, del que tenemos una excelente bibliografía: Fitzpatrick, Peter y Rüegg, Alfred, «Marxismo y derecho: una bibliografía en lengua inglesa» en Crítica Jurídica, Puebla, UAP, 1987, núm. 5, pp.169 y ss.

4 Vale la pena notar que la diferencia entre validez y efectividad, al menos en la literatura más conocida en América Latina, ha sido proporcionada por autores marxistas (tal vez por eso los positivistas no la recogen, empobreciendo sus análisis): Jeammaud, Antoine, «En torno al problema de la efectividad del derecho», en Crítica Jurídica, Puebla, UAP, 1984, núm. 1, pp. 5 y ss, (nótese que este trabajo fue presentado en las VII Jornadas de la Asociación Latinoamericana de Metodología y Enseñanza del Derecho, en México, en noviembre de 1982); el autor cita como antecedentes a Capella, Juan-Ramón, El derecho como lenguaje, Barcelona, Ariel, 1968, pp. 105 y ss, y Perrin, Jean-François y otros, Pour une théorie de la connaissance juridique, Ginebra/París, Droz, 1979, pp. 91 y ss., todos autores marxistas. Esta distinción conceptual fue recogida en Correas, Oscar, «Teoría Sociológica del Derecho y Sociología Jurídica» en Crítica Jurídica, Puebla, UAP, 1987/8, núm. 7 y 8 . En cambio no fue tomada en cuenta, creo que en perjuicio de su por lo demás notable trabajo, por Navarro, Pablo Eugenio, La eficacia del derecho, Madrid, Centro de Estudios Constitucionales, 1990, como para comprobar la notable reticencia de los autores analíticos a leer sobre Sociología Jurídica, y mucho más si proviene de los marxistas. Nótese que, si bien estos conceptos provienen, entre nosotros, de autores marxistas, no provienen en cambio de alguna parte de la teoría social de Marx; esto es, no es el marxismo en tanto pensamiento social el que provee de los fundamentos de estos aportes.

5 En España puede decirse que sucede un fenómeno especial: los marxistas no tienen ninguna dificultad teórica, que no política - con los analíticos, porque el marxismo español, tal vez gracias a Manuel Sacristán, no se ha desarrollado en la lógica de la oposición filosofía analítica vs. marxismo como, por ejemplo, en algunos países de América Latina. El libro de Juan-Ramón Capella citado en una nota anterior es un excelente ejemplo de un texto analítico, incluso pionero en la propia Teoría General del Derecho, escrito por un marxista. 6 Por ejemplo, Marí, Enrique E., «Racionalidad e imaginario social en el discurso del orden» en Doxa, Alicante, 1986, pp. 93 y ss, Correas, Oscar, Kelsen y los marxistas, México, Coyoacán, 1994.

7 Vale la pena decir que en el trabajo de Atienza y Ruiz Manero, citado más arriba, los autores dicen que los marxistas ignoran la Teoría General del Derecho; se basan para decir eso en el estudio de las obras de Edelman y Miaille, a quienes acusan de que, no sólo no conocen tal teoría, lo cual es cierto, sino de que combaten a esclerosados autores franceses sin ninguna importancia en el mundo filosófico jurídico actual, ganando así un combate contra figuras menores. Yo digo lo mismo de ellos: pueden denostar el marxismo jurídico, porque critican a marxistas que, efectivamente, no conocen la teoría contemporánea. ¿Porqué no prueban con latinoamericanos de la Teoría Crítica del Derecho?

8 «Ningunear» es un mexicanismo, irreemplazable en el idioma español, que no significa lo mismo que «ignorar», que puede incluir la idea de lo no intencional.

Problemata: R. Intern. Fil. v. 8. n. 1 (2017), p. 403-413

e-ISSN 2236-8612 